\title{
Outcomes-Based Education Integration in Home Economics Program: An Evaluative Study
}

\author{
Mark Raguindin Limon (Corresponding author) \\ Department of Technology and Livelihood Education, Mariano Marcos State University \\ College of Teacher Education, Ilocos Norte, Philippines \\ E-mail: mark_limon149@yahoo.com \\ John Paul Castillo Vallente \\ English Department, Mariano Marcos State University \\ College of Teacher Education, Ilocos Norte, Philippines \\ E-mail: johnpaulvallente24@gmail.com
}

\begin{abstract}
Received: April 4, 2016 Accepted: May 15, 2016 Published: May 17, 2016
doi:10.5296/jei.v2i1.9262 URL: http://dx.doi.org/10.5296/jei.v2i1.9262
\end{abstract}

\begin{abstract}
This study examined the factors that affect the integration of Outcomes-Based Education (OBE) in the Home Economics (HE) education curriculum of the Technology and Livelihood Education (TLE) program of a State University in the northern part of the Philippines. Descriptive survey and qualitative design were deployed to gather, analyze, and interpret data, which were deemed significant to the study. These research methods involved questionnaires, interviews, observations, and document investigations. The unit of analysis, which was purposively selected, was the students and faculty of the HE department under the TLE program. Results disclosed that there is little understanding of the new paradigm shift-OBE; there are limited instructional resources for the faculty; laboratory equipment were inadequate; and physical facilities available do not maximize the competencies required by OBE. Therefore, the researchers proposed the formulation of a new set of educational objectives, and the design of an action plan for the succeeding five years, in order to solicit necessary budget allocation from the government funding agency. This effort will address the identified gaps in the delivery of the OBE curriculum, specifically in upgrading physical resources and instructional materials. In addition, personnel involved in curriculum implementation should undergo seminars and trainings so that they could translate theories
\end{abstract}




\section{Macrothink

and concepts into practical skills and lifelong learning, which are needed for global marketability in the $21^{\text {st }}$ century.

Keywords: Outcomes-Based Education, Higher education, Home Economics, Technology and Livelihood Education, Physical facilities/resources, Educational policy and administration, Lifelong learning, $21^{\text {st }}$ century skills, Curriculum implementation

\section{Introduction}

Outcomes-Based Education was basically the result of urgent need to provide solutions to the identified gaps in the previous Philippine curriculum. Studies had proven that the traditional curriculum heavily emphasized academic achievement so that the task-based and output-oriented educational activities simply fell short of. Skills that keep in touch with the demands of the labor market and professional spheres were not necessarily incorporated in the delivery of the content. Curriculum experts underscored the following issues related to the traditional curriculum model in the Philippines: (a) the pedagogical decision-making process was within the confines of selected stakeholders, hence, other stakeholders were not represented in the development of the traditional curriculum; (b) since the curriculum was considered structured and prescriptive, it limited modifications by and flexibility from the teachers; (c) the curriculum was content-based, thus generally teacher-centered; (d) skills practice and mastery as reinforcements of the subject content became minor priorities; and (e) the curriculum prompted unhealthy competition as learners' assessments and evaluations were comparative in nature.

Due to these criticisms directed towards the traditional curriculum, OBE came to light. Spady (1994) propounded the basic tenets of Outcomes-based education (OBE); these were further specified in 2004 by Williams as being about the focus of educational activity from "teaching to learning; skills to thinking; content to process; and teacher instruction to student demonstration". Apparently, the transition from the profound focus on content-based learning to a future-oriented education curriculum grounded on the principles of pragmatism was clear and radical. 
Table 1. Outcomes Based Principles - explanation \& application by Spady (1994) and Killen (2000)

\begin{tabular}{|l|l|l|}
\hline OBE Principles & Explanation & Application to practice \\
\hline Clarity of focus & $\begin{array}{l}\text { Focus on what want learners be } \\
\text { able to do successfully }\end{array}$ & $\begin{array}{l}\text { Help learners develop competencies } \\
\text { Enable predetermined significant outcomes } \\
\text { Clarify short \& long term learning intentions } \\
\text { Focus assessments on significant outcomes }\end{array}$ \\
\hline Design down & $\begin{array}{l}\text { Begin curriculum design with a } \\
\text { clear definition of the } \\
\text { significant learning that } \\
\text { learners are to achieve by the } \\
\text { end of their formal education }\end{array}$ & $\begin{array}{l}\text { Develop systematic education curricula } \\
\text { Trace back from desired end results } \\
\text { Identity “learning building blocks" } \\
\text { to significant learner outcomes }\end{array}$ \\
\hline High expectations & $\begin{array}{l}\text { Establish high, challenging } \\
\text { performance standards }\end{array}$ & $\begin{array}{l}\text { Engage deeply with issues are learning } \\
\text { Push beyond where normally have gone }\end{array}$ \\
\hline Expanded opportunities & $\begin{array}{l}\text { Do not learn same thing in } \\
\text { same way in same time }\end{array}$ & $\begin{array}{l}\text { Provide multiple learning opportunities matching } \\
\text { learner's needs with teaching techniques }\end{array}$ \\
\hline
\end{tabular}

Nevertheless, with the implementation of OBE as the new curriculum in the Philippine higher education setting, issues on the preparedness of the implementers and the learning environment itself were raised. The first issue was providing a clear-cut description of the language associated with OBE and defining the essence of the term outcomes. In 1998, Jansen argued that the language associated with OBE is complex and at certain periods, contradictory - the very reason why trying to understand it initially leads to confusion. In order to prove his point, he quoted the definition provided by the South African National Curriculum Development Committee which asserted that Transformational OBE is a collaborative, flexible, transdisciplinary, outcomes-based, empowerment-oriented approach to learning. Berlach (2004) opined that the language used in OBE is corporatization applied to education. Further, in 2000, Prideaux also expressed his difficulty with the language, and reported that he felt uncomfortable when attempting to explain such a curriculum that imposes certain degrees of complexity.

In 2004, Williams specified that outcomes should be achievable and assessable; instruction should make a difference; they should be essential to all learners; should be transparent and fair; they should indicate where learners failed; and reflect the results of learning, not process. Tucker (2004) added to this definition by stating that OBE is a process that involves the "restructuring of curriculum, assessment and reporting practices in education to reflect the achievement of high order learning and mastery rather than the accumulation of course credits." Thus, the new curriculum is primarily targeted at facilitating desired changes within the learners, by means of fostering higher-order thinking, developing skills, and positively 
influencing attitudes, values, and judgments. The divergent perspectives on what underlying principles comprise OBE made transparent the insufficient attention given to technical coherence across concerned stakeholders. As a result, the interpretation of certain curriculum features by a learning area committee significantly differed from the others. Thus, achieving coherence throughout learning areas seemed unattainable. Though the nature of OBE and the underpinnings that fortify the curriculum had been subjected to heated debates, it was comprehensible that the paradigm shift was a direct retort to the previous curriculum, and that OBE's instructional planning process is a reverse of that associated with traditional educational planning. The desired outcome is selected first and the curriculum, instructional materials and assessments are created to support the intended outcome (Spady, 1988). All curriculum and teaching decisions are made based on what resources and methods will be used best to facilitate the desired final outcome. Certainly, OBE places extensive requirements from learning institutions in terms of educational equipment and physical facilities (resources) that would help materialize the goals and objectives of the curriculum, and more so, on the capacity of the educators to render the curriculum (method) in its maximum operation. Within these demands, Philippine schools, state universities in particular, experience problematic conditions.

The researchers centered the study on the students and faculty of the HE department, which is under the TLE program, of a State University in the northern part of the Philippines. The HE department is intended to provide laboratory experiences and reality-based simulations which enable college students to gain understanding of and acquire competencies in various economic activities related to the home and the community. It focuses on the development of responsible and worthy home membership that will lead to the strengthening of the family. The learning activities emphasize the development of desirable work attitudes, basic work skills and habits through learning situations relevant to everyday chores at home, school and community and the production of useful articles. The researchers believe that through OBE, and the State University's holistic preparedness in implementing it, the goals and objectives of the HE department would be comprehensively explored and realized.

This study is primarily based on the following questions: what conceptual framework of outcomes-based education exists among HE students and teachers; what kind of OBE-oriented resources and methods are used by the teachers in delivering HE learning areas to the students; what interventions can be offered to properly address gaps in the implementation of OBE within the field of HE; and what recommendations may be offered for classroom practice to realize the goals of OBE within the HE program?

\section{Methodology}

This part discusses the methodology utilized in collecting and analyzing data for the purpose of providing answers to the questions concerned in this study.

\subsection{Design}

The study used a descriptive survey research design where structured and unstructured questionnaires were employed in order to obtain data. 


\subsection{Research Instrument}

Data required for this study were collected by posting questions to the student- and teacher-respondents using questionnaires. Since questionnaire design is an activity that should not take place in isolation, the researchers consulted and sought advice from specialists and colleagues at all times during the construction of the questionnaire. The researchers ensured that adequate time was budgeted for the construction of the questionnaire. The aim of the questionnaire was to obtain information regarding OBE and its implementation in the Home Economics program, specifically in terms of: (1) availability of resources - educational and practical; (2) students' and teachers' reception and perception on the new curriculum; and (3) preparatory interventions for effective curriculum delivery of HE faculty. The questionnaire's response rates include: None (1), Few (2), About Half (3), Many (4), and Practically All (5).

\subsection{Validity and Reliability of the Instruments}

The instrument was subjected to face validation by three experts. Twenty copies of the instrument were administered to respondents who were not part of the sample. Cronbach Alpha formula was used to analyze the data. A reliability coefficient index of .75 was obtained and based on that, the instrument was adjudged reliable.

\subsection{Sampling}

The target population of the study was the students and faculty of the HE department in a State University in the northern part of the Philippines. Simple random sampling technique was used to select the sample for the study. This sampling technique was chosen in order to obtain a true representation of the population.

\subsection{Method of Data Collection and Analysis Technique}

Copies of the questionnaire were distributed by research assistants trained by the researchers and assigned to the faculty-in-charge and students in Home Economics of the State University. The questionnaire was administered on-the-spot and collected by the research assistants. This style was chosen to ensure $100 \%$ receipt of the questionnaire. Aside from the questionnaire used, interview and observation were also used as methods in collecting data.

\section{Results and Discussions}

The discussions are arranged according to the major concerns of the study: students' and teachers' conceptual framework of Outcomes-Based Education; kinds of OBE-oriented resources and methods deployed by HE teachers to deliver instruction; possible effective interventions that can satisfactorily address the gaps in the implementation of OBE within the field of $\mathrm{HE}$; and recommendations to improve classroom practice as a way of realizing the goals of OBE within the HE program.

\subsection{Students' and Teachers' Conceptual Framework of Outcomes-Based Education}

Understanding of $O B E$ terminology. The majority of respondents were able to provide definitions and principles pertaining to OBE however the ideas gathered lie on the surface 
level comprehension of the term. $93 \%$ from the responses were devoid of information as to how OBE and the HE program link together to produce skilled and competitive graduates, while the remaining 7\% discussed about additional course requirements as a result of the output-based learning activities stipulated by the new curriculum-these answers only marginally touches on the more complex relationship that exists between OBE and HE program. It was very clear that the interpretation of some of the features in the OBE curriculum varied across the sample, thus, coherence in the curriculum's general goals, specific objectives, academic expectations, and learning outcomes was not attained, even at the initial implementation phase of OBE in the State University. This finding is alarming because any curriculum shall not operate at its optimum if stakeholders primarily involved and affected in its implementation do not hold on to a uniform concept of the curriculum.

Support from school management. An overwhelming percentage of the respondents $(87 \%)$ claimed that they were not rendered valuable services from the management team, which included the personnel of the administration who are expected to disseminate significant information on the new curriculum through symposiums, seminar-workshops, or departmentalized trainings. The recurrent reason for such negligence of duty was that the individuals concerned with orienting the general school population about the new curriculum were preoccupied with national and international fieldwork; therefore, scheduled mass orientations were facilitated by alternates who lack knowledge and expertise about the curriculum. Formal and informal relationships with the team are not only important features of a "teacher-student" life, but may also have a considerable influence on OBE teaching and general behavior in the classroom instruction. The respondents stated that the team, including the alternates, must have thorough knowledge of all matters regarding all important aspects on curriculum matters because they expect leadership from them.

\subsection{OBE-Oriented Resources and Methods Deployed by HE Teachers to Deliver Instruction}

Learning materials used in classroom. It was found out from the interview that there are only minimal resources that satisfy the academic demands and standards of the OBE-based learning objectives in the HE program. The State University has a laboratory building, but that equipment to carry out simulations, demonstrations, and practicums are insufficient and are classified "below average" when it comes to quality and standard. Furthermore, print materials such as books, modules, manuals, and informational brochures are commonly not provided to the teachers and students, thus, the respondents reported that they needed to provide resources for their own which is frequently one of the main causes why they experience time-deficiency for instruction and student-performances. These educational struggles are typical of rural state universities, where budget allocation was limited at the minimum, thus, could not substantially cover the cost of operation and implementation of a new curriculum, especially one which is demanding such as the OBE. The lack of funding eventually leads to limited course offerings due to insufficiency of facilities that could accommodate meaningful learning for large-group classes, and shortage of able faculty who are competent enough to deliver course content in accordance with the OBE principles.

Teacher-learner-ratio conducive to respondents. $92 \%$ of the respondents agreed with the 
statement that teacher-student ratio affects individual assistance in an HE classroom situation, most especially during practical performances where teacher's scaffolds become crucial in the attainment of objectives. It is a universal knowledge that the levels of learning factors vary between learners. Each student's specialized needs should be addressed by the teacher in a manner that considers diversity in learning style of the students. Classes with too many students would make the effort of giving attention to individual learners difficult, and almost impractical. In addition to this, classroom management becomes a serious instructional issue. There is not enough space for the teachers and students to carry out their expected performances in class. Also, resources available for learners in the class become insufficient. Certainly, the high number of students in a course offering would probably decrease the degree of teacher's engagement with his/her learners. $85 \%$ of the respondents reported that the HE department is without adequate furniture for OBE. One example provided during the interview was the lack of enough chairs for every student in the class. Teacher-respondents opined that most of the time, active involvement of students in the class would depend on the sitting arrangement, which include balance between the number of chairs and class population, quality and physical attributes of the chair, and how seats are organized based on the day's major activity. Furthermore, as revealed in the survey and interviews, the HE department is in short supply of safe water, electricity, and recreational resources. While approximately $82 \%$ of the overall buildings in the HE department has power supply, thus permitting the use of electronic multimedia resources-television, computer, and projectors - in lesson delivery, $18 \%$ is incapable of operating electronic media, thereby, teachers employ alternative instructional materials that oftentimes do not effectively translate the provisions of the OBE. Interview and ocular visits suggested immediate action from the government, specifically in supplying as many resources as possible to capture the OBE curriculum in its fullest sense. Complete learning resources can contribute towards positive learning experiences as they offer the individual learner an opportunity to develop his/her full potential (Treloar, 2002).

The educational resources listed in the succeeding tables resulted from the interview sessions of student- and teacher-respondents conducted by the researchers. The respondents were asked about what resources they believe are needed in order to effectively translate the curricular bases of OBE into actual, meaningful pedagogical application. The categories under which their answers can be classified are presented in separate tables.

Based on the responses of the students and the teachers, the researchers performed an inventory of the available resources from the State University in order to find out if the existing physical facilities and instructional materials in the school's HE department meet the expectations of two of its major stakeholders - the teachers and the students. 
Table 1.Common Home Economics laboratory tools and equipment

\begin{tabular}{|c|c|c|}
\hline Basins* & Forks* & Sewing machines ${ }^{\wedge}$ \\
\hline Bed covers* & Framed painting $^{\wedge}$ & Sewing needles* \\
\hline Beds (single)* & Glassware* & Shredders $^{\wedge}$ \\
\hline Cabinets $^{\wedge}$ & Information corner ${ }^{\wedge}$ & Silverwares $^{\wedge}$ \\
\hline Canisters* & Iron greaters $^{\wedge}$ & Spoon* \\
\hline Colanders* & Ironing board ${ }^{\wedge}$ & Stoves* \\
\hline Comfort room* & Kettle* & Strainer* \\
\hline Coolers $^{\wedge}$ & Kitchen board* & Tape measures* \\
\hline Cutting tools* & Lavatory* & Tea bottle ${ }^{\wedge}$ \\
\hline Demonstration mirror $^{\wedge}$ & Lighting system* & Teacher's table ${ }^{\wedge}$ \\
\hline Dining tables* & Mat* & Thermo jug $\wedge$ \\
\hline Dish towels* & Measuring cups/glasses* & Towel (hand \& face)^ \\
\hline Display cabinets for models ${ }^{\wedge}$ & Meat grinders $^{\wedge}$ & Trays* \\
\hline Dressing rooms $^{\wedge}$ & Medicine kit* & Utility kitchen cooking tools^ \\
\hline Dressing shears $^{\wedge}$ & Microwave oven* & Washing facilities* \\
\hline Egg beaters* & Mortar \& pestle* & Waste can/garbage can* \\
\hline Embroidery scissors* & Oven* & Water container $^{\wedge}$ \\
\hline Fitting/life sized mirror* & Refrigerator* & Water dispenser* \\
\hline Flat irons* & Sala set* & Water supply* \\
\hline Flower vases* & Sauce pans ${ }^{\wedge}$ & Window curtain^ ${ }^{\wedge}$ \\
\hline Food containers $^{\wedge}$ & Scissors* & Working tables $^{\wedge}$ \\
\hline
\end{tabular}

Note. ${ }^{*}=$ Available ${ }^{\wedge}=$ Not available.

Apparently, as shown in Table 1, a substantial amount of important laboratory tools and equipment is not accessible in the department. Due to these unpreparedness when it comes to facilities and equipment, teacher-centered approach to OBE was employed, which is defeating the new curriculum's most fundamental principle. According to the teacher-respondents, if the number of students goes so much more beyond the ideal, which is 30 students per classroom, a learner-centered approach can never truly be carried out.

Most instructional materials required to integrating interactive, multimodal, and authentic classroom discussions and presentations, such as LCD projectors and models are absent; the majority of available resources are those that bend towards the traditional approach in teaching, namely chalk/white boards, and textbooks, as exhibited in Table 2. 
Table 2. Instructional resources needed to carry out OBE

\begin{tabular}{|c|c|}
\hline Charts* & Bulletin board* \\
\hline Cut outs* & Pocket charts* \\
\hline Demonstration boards $^{\wedge}$ & Modules $^{\wedge}$ \\
\hline Display boards* & Flash cards* \\
\hline Chalk/white boards* & Posters $^{\wedge}$ \\
\hline Graphs* & Teaching Materials* \\
\hline Models $^{\wedge}$ & Workbooks/manuals* \\
\hline Diagrams* & Supplies $^{\wedge}$ \\
\hline Textbooks/references* & Overhead projectors^ ${ }^{\wedge}$ \\
\hline Magazines $^{\wedge}$ & Opaque projectors $^{\wedge}$ \\
\hline Brochures $^{\wedge}$ & LCD projectors and screen^ ${ }^{\wedge}$ \\
\hline Displayed projects* & 30 " flat screen $\mathrm{TV}^{\wedge}$ \\
\hline Panel board* & Interactive white board ${ }^{\wedge}$ \\
\hline
\end{tabular}

Note. ${ }^{*}=$ Available; ${ }^{\wedge}=$ Not available.

In Table 3, it is clear that teachers in the State University engage their students in all types of assessment procedures, which is essential since it enables teachers to evaluate different skill sets in diverse conditions. Nevertheless, it is important to note that most of the performance-based and product-based assessments do not include contextualized rubrics. In addition, the rubrics that were utilized are holistic, which is not recommended for beginning teachers since its use requires high level of expertise in carrying out evaluation procedures.

Table 3. Assessment of/for learning to be used in OBE

\begin{tabular}{|l|l|}
\hline Oral testing* & True or false* \\
\hline Completion type* & Reaction papers* \\
\hline Essay type* & Oral reports* \\
\hline Performance* & Essays* \\
\hline Matching type* & Project/outputs* \\
\hline Multiple choice* & Written reports* \\
\hline
\end{tabular}

Note. ${ }^{*}=$ Available; ${ }^{\wedge}=$ Not available.

The physical facilities available in the Home Economics department of the State University are obviously largely associated to the field's food preparation subcomponent since the other facilities needed to facilitate other subcomponents, such as cosmetology room, caregiving 
room, and exhibit hall are not given much attention, as can be observed in Table 4. In order to produce graduates from the program who can perform competently in most subcomponents of the field, then students should be provided platforms to practice skills specific to each subcomponent.

Table 4. Physical Facilities needed in Home Economics for the OBE

\begin{tabular}{|c|c|}
\hline Sewing room ${ }^{\wedge}$ & Home Economics specialized room $^{\wedge}$ \\
\hline Cooking room* & Cosmetology room/Salon ${ }^{\wedge}$ \\
\hline Kitchen* & Bar tending room ${ }^{\wedge}$ \\
\hline Practice house* & Washing nook* \\
\hline Storage room* & Entrepreneurial room ${ }^{\wedge}$ \\
\hline Exhibit hall^ & Simulation room (restaurant, program hall, etc)^ \\
\hline 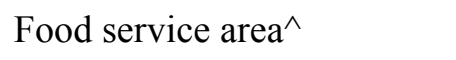 & Care giving room ${ }^{\wedge}$ \\
\hline Home economics e-library $^{\wedge}$ & Clinic* \\
\hline
\end{tabular}

Note. ${ }^{*}=$ Available; ${ }^{\wedge}=$ Not available.

OBE entails the use of student-centered approach so that the full potentials of students in executing skills relevant to their courses or program can be harnessed in a manner that involves collaboration, results, and feedback. However, in Table 5, it is shown that the teaching methods employed to deliver the curriculum lean against the principles of teacher-centered approach, where most of the instructional time is apportioned for lecture discussion, and board and seatwork.

Table 5. Teaching method and instructional aids

\begin{tabular}{|l|l|}
\hline Lecture-discussion* & Creative appreciation \\
\hline Experimental $^{\wedge}$ & Remedial instruction $^{\wedge}$ \\
\hline Laboratory work* $^{*}$ & Panel$^{\wedge}$ \\
\hline Group discussion* & Forum $^{\wedge}$ \\
\hline Lecture* & Board and seatwork* $^{*}$ \\
\hline Case study & \\
\hline
\end{tabular}

Note. ${ }^{*}=$ Available; ${ }^{\wedge}=$ Not available.

Problems in Curriculum implementation. Due to the limited facilities and faculty resources of the HE department, sharing of student to the other college was allowed. Some features of the HE OBE-based curriculum should be modified to reflect reform in the priority needs. Effects must be directed towards developing programs that are different from those existing. 
Curriculum in Home Economics must be based on the human nature like age, sex and maturity level so that learners could conveniently adapt themselves to whatever kind of curriculum is being offered. Students' curriculum adaptation should also be fulfilled by way of association of human potential to the level of skills integrated in the curriculum.

Inadequacy of Physical facilities. The general impression is that there is inadequacy in all types of physical facilities. The same observation is made in laboratories, shops, office, toilets, clinic, library, and others. These findings indicate that this inconvenience, certainly, affects the efficiency of the HE department in a very significant way. The teachers could not prepare for the reading lessons in the room, and the study habits of students are greatly affected for the reason that they cannot be served well, and there is no enough space to move out or relax in between classes or during their vacant periods. (1) As to the appraisal of supply, lighting and ventilation the respondents gave a satisfactory rating. However, succeeding results apparently show that facilities in general are below the standard. These are essential factors, which if given urgent attention and if adequately provided will make instruction efficient and learning conducive. Good health and sanitation can be promoted with sufficient and continuous supply of water, proper lighting and ventilation; (2) Instructional facilities. Considering the fact that instructional resources are highly regarded in the formulation of curriculum for each department, the availability and quantity of instructional facilities in accordance with teachers' population and specializations should thereby meet standards. It reveals that the department is yet to procure additional equipment as preparatory steps for the integration of the OBE curriculum; (3) Sufficiency of books in the library. Accounts from interviews show that printed materials, particularly books needed for research and other academic-related endeavors are not enough. On this basis, it can be said that the State University is insufficient in terms of HE-concentrated reference materials that are directly needed in the delivery of the curriculum. Since the HE department offers courses that require technical skills, the State University, as support, should acquire abundant library resources; (4) Availability of library depends on students. Concerning the aforementioned issue, the HE students commented that their study loads are too heavy; they do not have much time left for self-study in the library. The researchers agree with the group of teachers and students that there is no time provided for the students to do library work, even assuring that there is adequate service in the library. The effect is that the students will be largely dependent on their teachers during class hours for whatever knowledge they will have to gain. With their situation, there will be much less to be acquired by these students than when they will be given ample time for library work; (5) Adequacy of tables, chairs and furniture. From the observation of the researcher, it can be stated that the school have yet to meet the minimum requirements in order to satisfy the convenience of all concerned in the teaching-learning process and office works.

Teaching methods and instructional aids. The researcher was also concerned with the kinds of teaching methods and instructional aides which are predominant among the teachers. The interviews conducted with the respondents indicate that combinations of the instructional methods were employed by the teachers and to whenever the need arises. The above finding shows that the most effective methods of teaching the TLE as a subject may vary from 
subject to subject. This impression, however, does not preclude the need to use instructional aide in maximizing the efficiency of instruction in various subjects, while no doubt; there will be advantage when they are used. Availability of special kinds of instructional materials. With the knowledge that the proper use of audio-visual equipment and other instructional aide can facilitate teaching in all subjects, there must be available equipment such as slide projector, televisions, and movie projectors. The availability of the afore-stated instructional aides connotes that the school has exhausted all means in ensuring the efficiency of instruction. Controlling and evaluating the achievements of the student. In as much as the evaluation of the achievements of the student is a part of the overall program of instruction. The practices in this regard are covered in this study. It reveals that out of the total responses cited the means of evaluating the achievement of the students were quizzes, long exams, daily recitations, project accomplished, experiments, laboratories, skills assessment and seat and board work. It can be noted that the university if following common practices of SUCs in evaluating students' performance.

\subsection{Possible Effective Interventions that can Satisfactorily Address the Gaps in the Implementation of $O B E$ within the Field of $H E$}

The need for intensive Outcomes-Based Education training. Among students and teachers in the HE department, 93\% were able to provide an acceptable definition for the term OBE, however, these definitions were highly concentrated with the general orientation to the terminology, with minimal attention to the guiding principles of the new curriculum and how it could be carried out to reinforce learning in Home Economics. Through this finding, it is without doubt that the central stakeholders in the educational process are not adequately trained with regard to the new curriculum. Teacher-respondents claimed that there were trainings conducted that were patterned after the cascade model, but in most cases, the expert trainers were sent to national seminars or international conferences, therefore, the State University would frequently seek for replacements, who do not fully understand the substance of OBE, and consequently fail to apply its principles in their actual teaching methodologies. It was a consistent recommendation that the quantity of trainings should not be the top priority, but it should be the quality of these interventions. There were also suggestions on the representation of other concerned stakeholders - parents, NGOs - during the conduct of OBE trainings.

Accessibility of resources and other instructional scaffolds. The HE department should plan serious and urgent actions on procurement of additional resources for the maximum operation of OBE. When resources are made available for both teachers and students, trainings aimed at educating the users on the materials' appropriate usage becomes imperative. This scheme would help in preserving the quality of the resources, so that these could function within considerable time frames. The government should be informed through resolutions, inventories, and reports on the existing conditions of infrastructures and other physical facilities of the HE department in the State University. It is expected that the government views these formal accounts as alarming educational issues that need long-term solutions.

The need for improvization. When the State University is unable to provide the needed 
resources for the curriculum's full implementation, the pedagogical decision is mainly left on the teacher. In this case, the teacher should know how to improvise by the use of alternatives, however, these should not largely affect the quality of learning delivered to the students. Alternatives such as teacher-made charts, models, posters, flashcards, and brochures can complement those available resources in the department. Innovative and resourceful teachers could always find a way on how content and practice are rendered even without complete learning materials. Some of the teacher-respondents interviewed did not only use personal financial resources but they needed to ask for contributions from students who are financially able in order to procure some equipment necessary for practicum and individual or group performances. The researchers advise that extreme care must be taken when asking students to contribute materials for practical learning areas so that those who are not capable in making contributions are not discriminated.

Proper care and handling of resources. In order to mobilize and maximize the resources to the full and complete benefit of its clienteles - teachers and students - they should be treated and handled properly. Training students and teachers to handle resources with utmost care is one of the key task areas of the organizational manager. Strictly implemented policies and procedures that focus on the quality maintenance of physical facilities and tangible learning materials should be disseminated to the immediate and secondary users. For example, at the end of each term, under supervision, an in-charge must visit all classrooms to tighten up screws and the necessary small repair to classroom furniture. Loss of state property through theft, fire or any form of fraud must be immediately reported to the authorities. All available information must be reported to the authorities, including the district office managers at the earliest possible opportunity. School property may under no circumstances be lent to individual for private use. Resources may not be sold by the school unless permission has been obtained in writing from the higher ups, and the arrangements for pricing and payment of money accrued from such sales determined. Proper control is a key aspect in the managing of resources. Students are not allowed into stockrooms unless under the supervision of a responsible adult. It is vitally important that the school or department manager keeps a firm hand on the control of educational resources in the school.

The need for multi-skills. Outcomes-Based Education as a new system needs skilled and adequately-trained implementers, which include teachers, heads of departments, and deans. HE teachers, in particular, will have to engage themselves in the culture of multi-skilling. Although teachers must be experts in a specific field of specialization in Home Economics, they should also be open to interdisciplinary possibilities such as learning complex skills in the program - handicraft, clothing and textile, and food nutrition. This flexibility among the teachers will help the HE department reach its desired goals and targeted learning outcomes. Teachers will not only be empowered or provided with alternate jobs for themselves but they will also transfer multi-skilling qualities to Filipino students who, in the near future, can serve the country productively.

Intensification of competent teacher population and platforms for professional growth. To achieve a teacher-student ratio of 1:30 by the year 2020, an increase of some educators would be required. There is a great shortage of HE teachers in the TLE program, thus, efforts on 
broadening the scope of recruitment procedures in this field should be taken into account. The State University might consider the advantage of online websites in advertising purposes, where they could connect with professionals beyond the confines of the locality.

The new system of education is aiming at the optimal development of individual talent and the improvement of the quality of life of people, therefore it requires for its successful implementation, a sufficient number of qualified teachers. To achieve an army of OBE ready teachers, the Commission on Higher Education (CHED) must first promote professional growth among the educational workforce by means of staff development programs, such as crash-courses offered to interested members of the State University every weekend or summer. The institution, specifically the concerned department, should also allow teachers to pursue graduate studies, and perform load revisions or reforms in the teaching assignments as forms of support. Scholarship grants and funding may also be extended within this context.

\section{Recommendations to Improve Classroom Practice as a Way of Realizing the Goals of OBE within the HE Program}

(1) If individual practicum is unfeasible because of a heavily populated class, group and paired demonstrations or performances could be an effective alternative. Experts in the field may be invited to help facilitate evaluation of outputs in cases when individual exhibitions are required by the learning objectives. Teachers may also arrange separate schedules for the conduct of performance-based assessments in order to carry out proper guidance during individual presentations. Allowing students to accomplish tasks by themselves foster decision-making, self-confidence, and independence; (2) Learning materials for learners should be well provided. This would encourage active learning and full participation by all learners. The implementation of OBE and the utilization of resources should be coupled with motivating learners to extensively exhaust available resources; (3) Because OBE is student-centered, it places more demand from the learner when it comes to performing and accomplishing tasks and assignments. Within this challenging learning environment, the parents come into play. Parents' role in the completion of homework, preservation of learning materials, meeting of project deadlines, etc. is of paramount importance. Thus, they should also be involved during OBE orientations, and on occasions when certain revisions in the curriculum are made; (4) Partnerships with NGOs and private agencies that may aid in the supply of affordable yet quality materials useful in the implementation of the new curriculum should be encouraged. By actively participating in linkages outside the educational system, needed resources may be provided. Nevertheless, business transactions with external organizations should be subjected to approval by concerned stakeholders for transparency of pedagogical decision-making.

\section{Conclusion}

At the turn of the century, the status quo in the Philippine educational system is challenged by a new curriculum-OBE. It opens fresh pedagogical approaches to teachers, at least in the country's context that redirect them from the bland uniformity in content and academic focus to a dynamic, diverse, multidisciplinary, and output-oriented teaching-learning environment. Though, the paradigm shift were confronted with a number of criticisms that identified gaps 
and issues in the new curriculum, the reality cannot be overlooked that when carried out properly, OBE can provide better educational experience to the learner and prepare him/her to contribute significant impact in the global market, after graduation.

The Home Economics program tone with the fundamental tenets of the OBE curriculum in that both provide opportunities for education, research, extension and community outreach, and industry-job-training activities that seek to empower the Filipino families in the drastically changing society in the 21 st century. There were problems identified in this study towards the operation of OBE in the HE program like inadequate instructional facilities and learning materials, lack of well-trained teachers who could help realize the objectives of the new curriculum, mismatch between student population and the number of teachers for the different courses, and other issues that were touched in the discussion of the aforementioned. However, this study has set feasible and effective interventions that the HE department in the State University of Region 1 could incorporate in the design of an action plan for the next five years. The various stakeholders involved in the department must work hand-in-hand in order to fill in identified gaps with long-term solutions in order to fully capture the essence of Outcomes-Based Education.

\section{References}

Berlach, R. G. (2004). Outcomes-based education and the death of knowledge. Australian Association for Research in Education., 2-11. Retrieved from http://researchonline.nd.edu.au/cgi/viewcontent.cgi?article $=1000 \&$ context $=$ edu_conference

Jansen, J. D. (1998). Curriculum reform in South Africa: A critical analysis of outcomes-based education. http://dx.doi.org/10.1080/0305764980280305

Killen, R. (2000). Outcomes-based education: Principles and possibilities. Retrieved from http://drjj.uitm.edu.my/drjj/conference/upsi/obekillen.pdf

Prideaux, D. (2000). The emperor's new clothes: From objectives to outcomes. Medical Education, 34, 168-169. http://dx.doi.org/10.1046/j.1365-2923.2000.00636.x

Spady, W. G. (1988). Organizing for results: The basis of authentic restructuring and reform. Educational Leadership, 46(2), 4-8.

Spady, W. G. (1994). Outcome-based education: Critical issues and answers. ERIC database, ED380910.

Treloar, D. (2002). Outcomes-based education and standards for the University of Western Australia (Internal discussion paper, University of Western Australia).

Tucker, B. (2004). Literature review: Outcomes-focused education in universities. Retrieved from http://lsn.curtin.edu.au/outcomes/docs/LitReview.pdf

Williams, B. (2004). Self-direction in a problem-based learning program. Nurse Education Today, 24, 277-285. http://dx.doi.org/10.1016/j.nedt.2004.01.008 


\section{Copyright Disclaimer}

Copyright for this article is retained by the author(s), with first publication rights granted to the journal.

This is an open-access article distributed under the terms and conditions of the Creative Commons Attribution license (http://creativecommons.org/licenses/by/3.0/). 